\title{
Use of the Talk Test for Comparison of Exercise Intensity between Aerobic Activities with Treadmill and Bicycle
}

\author{
Yonghyun Kwon, Jong Sung Chang \\ Department of Physical Therapy, Yeungnam University College, Daegu, Korea
}

Purpose: The talk test (TT) is an alternative, self-reported method for prescribing and guiding exercise training in both healthy adults and patients with cardiovascular and pulmonary diseases. This study examined whether the $\Pi$ is a valid tool for evaluating the exercise intensity during two different types of aerobic activity on a treadmill or stationary bicycle in a healthy population.

Methods: A total of ten subjects (six males and four females) who had no medical history related to musculoskeletal, cardiovascular, and pulmonary disorders were enrolled in this study. They were evaluated using the $\Pi$, which consisted of three-level of difficulties demanding cardiac loads while performing aerobic activities on a treadmill and bicycle ergometer across two consecutive days in a counterbalanced manner. During the activities, the psychophysiological response markers were collected in terms of the heart rate, oxygen saturation, rating of perceived exertion, and metabolic equivalents.

Results: Statistical analyses revealed a significant difference in the between-subject variance regarding the $\Pi$ level effect $(p<0.05)$. On the other hand, no significant findings were detected on the between-group variance $(p>0.05)$ and the $\Pi$ level $\times$ group interaction $(p>0.05)$. The independent t-test indicated no significant differences in heart rate, oxygen saturation, rating of perceived exertion, and metabolic equivalents at any levels of the $\Pi$ in the two groups. The $\Pi$ showed a strong correlation with the rating of perceived exertion. Conclusion: This study showed that the $\Pi$ is a valid and alternative tool for evaluating the aerobic exercise intensity in a healthy population. In addition, differences in the psychophysiological response markers between two aerobic activities, treadmill and bicycle ergometer, were detected in the same exercise intensity scaled with the $\Pi$. The $\Pi$ can be used to evaluate and prescribe the exercise intensity of aerobic activity in cardiovascular and pulmonary physical therapy.

Keywords: The talk test, Psychophysiological response markers, Aerobic exercise, Exercise intensity

서 론

유산소 운동은 산소를 이용한 에너지 대사 처리 방식에 기초한 저강 도의 신체적인 운동을 말하는데, 폐기능의 증가, 혈액 순환의 증진, 당뇨와같은 대사성 및 심혈관성 질환의 예방 등의 효과를 가지고 걷 기, 자전거, 수영, 트레드밀 등의 다양한 방법으로 적용된다.1,2 특히 바 쁜 현대사회에서 트레드밀(treadmill) 또는 안정식 자전거(stationary bicycle)를 이용한 유산소 운동이 실내에서 매우 보편적으로 사용되 고 있으며, 심장 및 호흡계 질환을 가진 환자의 심혈관 기능을 유지 또는 증가시키기 위해서나 신경계 손상으로 인해 유산소 기능 증진 을 위한 환자들에 사용되고 있다. ${ }^{3-5}$

정신 생리학적 반응 지표(psyhophysiologic response markers)는 유
산소 운동의 강도를 측정하거나 운동 처방(exercise prescription)을 하 기 위한 기본적인 생체 정보로서, 여유심박수(heart rate reserve), 여유 산소섭취량(oxygen uptake reserve), 심박수(heart rate, HR), 대사당량 (metabolic equivalents, METs), 운동자각도(rating of perceived exertion, $\mathrm{RPE}$ ) 등이 있다. ${ }^{6}$ 심박수, 최대산소섭취량, 젖산 변화량과 같은 생체 자료의 수집은 측정하기 위한 장비가 필요하고 여러 외적 환경에서 수집하기 어려운 경우가 있을 수 있다. 반면, 운동자각도검사 또는 대 화 검사(Talk test)와 같이 운동의 강도를 주관적인 방법으로 측정하 는 방법은 매우간편하게 측정할 수 있는 장점이 있다.

대화 검사는 운동의 강도와 같은 생리학적 역치(physiologic threshold)를 간단하게 측정할 수 있는 검사로서, 1939년에 Grayson 교수가 전문 산악인에게 말을 할 수 있는 단계보다 빠르지 않게 등산하도록
Received Mar 11, 2020 Revised Apr 8, 2020

Accepted Apr 14, 2020

Corresponding author Jong Sung Chang

E-mail jackscjs@hanmail.net
Copylight (C)2020 The Korean Society of Physical Therapy

This is an Open Access article distribute under the terms of the Creative Commons Attribution Non-commercial License (https:// creativecommons.org/license/by-nc/4.o.) which permits unrestricted non-commercial use, distribution, and reproduction in any medium, provided the original work is properly cited. 
권고하는 조언에서 시작되었고 캐나다에서 "호흡 체크 검사(breath check test)"로 창안되었다. ${ }^{78}$ 대화 검사는 검사대상자가 유산소 운동을 수행하는 동안, 편안한 상태에서 말을 할 수 있는 단계, 말을 하기가 다 소 곤란한 단계, 말을 하기가 매우 어려운 단계로 점차 증가시키면서 대상자 스스로 자각하는 운동의 강도를 평가하는 방법이다. 만성 호 흡기 및 심장 질환이 있는 환자, 운동 선수, 일반인에게서 복잡한 측정 방법을 대신하여 간편하게 검사할 수 있는 도구로 알려져 있다. ${ }^{89}$

유산소 운동을 하는 동안, 운동의 자각도 및 생리학적 반응 지표 는 운동의 강도와 적절한 운동을 처방하기 위해 중요한 정보이다. 운 동 자각도 평가와 같은 주관적인 운동 강도 측정은 보편적으로 사용 하고 있지만, 대화 검사는 호흡 및 심장재활 분야에서 널리 알려져 있 지 않다. 임상에서 호흡 및 심장질환을 가진 환자에게 간단하게 사용 할 수 있는 임상 평가 방법이 많지 않고 대부분 기계를 사용한 정량적 인 생리학적 지표를 측정하는 것이 일반적이다. 한편, 실내에서 유산 소 운동을 수행하기 위한 가장 일반적인 운동 방법이 트레드밀과 고 정식 자전거를 이용하는 것이다. 몇몇 선행연구에 따르면, 트레드밀 과 고정식 자전거를 이용한 유산소 운동에서 자각적 운동 강도는 낮 고 효율적으로 심호흡계 기능을 증진시키는 것에 대한 비교연구가 출판되고 있다.8,10-13 따라서 본 연구에서는 대화 검사를 활용하여 각 각의 운동 강도 단계에서 트레드밀과 고정식 자전거를 이용한 두 가 지의 서로 다른 유산소 운동의 생리학적 반응 지표 및 자각적 지표의 차이를 비교하고자 한다.10,13

\section{연구 방법}

\section{1. 연구대상}

연구대상자들은 25 세 이상 35 세 미만의 정상 성인 10 명을 대상으로 시행하였다. 선정 기준은 정상적인 일상생활이 가능하고, 자세조절 및 보행에 장애가 없으며, 과거 병력 및 의학적 검사에서 심장질환이 없는 자로 하였다. 제외 기준은 흡연 이력이 있는 자, 장거리 육상 및
수영과 같은 전문적인 유산소 운동 선수, 전날 음주를 한 자로 하였 다. 대상자들은 본 연구의 목적과 절차에 대한 설명을 듣고 자발적으 로 참여의사를 밝혔으며, 연구동의서에 동의하였다.

\section{2. 측정도구}

1) 호흡가스분석기

호흡가스분석을 위해 자동호흡가스분석기인 Quinton Q-stress system with treadmill (Quinton, USA)을 사용하였고, 대상자의 대화 검사 의 운동 강도를 확인하기 위해 산소포화도 $\left(\mathrm{SaO}_{2}\right)$, 분당심박수, 대사 당량 등을 측정 및 분석하였다. 측정은 휴식 상태, 대화 검사 $1,2,3$ 단 계에서 각각 측정하였다. 모든 대상자는 $20-25^{\circ} \mathrm{C}$ 의 온도와 $50-55 \%$ 의 습도를 유지한 상태에서 오후 4 시에서 6 시 사이의 같은 시간에 실험 을 진행하였으며 피로도를 고려하여 48 시간 이상의 휴식을 취한 후 2 번째 실험을 진행하였다.

\section{3. 실험방법}

연구대상자는 실험 전 24시간 동안 운동을 제한하였고, 트레드밀에서 대화 검사와 고정식 자전거에서 대화 검사의 학습 효과를 방지하기 위 해 무작위로 선택하여, 최소 2 일 이상의 기간으로 같은 시간 다른 요일 에 수행하였다. 두 가지 대화 검사에는 대상자에게 운동 수행 중에 대 화를 수행하는 것이 포함되어 있으며, 운동 분석을 위한 측정 시 마지 막 단계에서 트레드밀 또는 자전거 운동 수행과 “국기에 대한 맹세” 낭 송을 동시에 수행하며, 낭송을 편하게 할 수 있는지에 대해 예 또는 아 니오라고 대답을 하도록 하였다. 대화 검사는 1단계: 편안하게 읽을 수

Table 1. Demographic information of subjects

\begin{tabular}{lcc}
\hline & Mean \pm sd & Range \\
\hline Age $(\mathrm{yr})$ & $28.40 \pm 1.84$ & $25-30$ \\
Height $(\mathrm{cm})$ & $167.80 \pm 8.23$ & $152-178$ \\
Weight $(\mathrm{kg})$ & $69.10 \pm 15.95$ & $46-90$ \\
Body mass index & $24.26 \pm 3.93$ & $19.91-28.73$ \\
\hline
\end{tabular}

Table 2. Heart rate, saturation of oxygen, rating of perceived exertion, metabolic equivalent of task in the two groups according to four different aerobic exercise conditions

\begin{tabular}{llcccc}
\hline & & Resting & T level 1 & T level 2 & T level 3 \\
\hline Treadmill Group & $\mathrm{HR}(\mathrm{bpm})$ & $81.20 \pm 8.57$ & $101.10 \pm 13.18$ & $122.30 \pm 20.91$ & $144.80 \pm 18.05$ \\
& $\mathrm{SaO}_{2}(\%)$ & $97.70 \pm 0.82$ & $97.70 \pm 0.95$ & $97.00 \pm 0.94$ & $97.40 \pm 0.52$ \\
& $\mathrm{RPE}(\mathrm{score})$ & $7.40 \pm 0.84$ & $8.30 \pm 0.95$ & $10.80 \pm 1.40$ & $14.10 \pm 1.60$ \\
Bicycle Group & $\mathrm{METS}\left(\mathrm{w} / \mathrm{m}^{2}\right)$ & $1.32 \pm 0.35$ & $2.98 \pm 0.59$ & $4.81 \pm 1.32$ & $6.64 \pm 1.19$ \\
& $\mathrm{HR}(\mathrm{bpm})$ & $80.60 \pm 6.65$ & $98.80 \pm 12.44$ & $120.40 \pm 16.18$ & $136.00 \pm 16.72$ \\
& $\mathrm{SaO}(\%)$ & $98.10 \pm 0.57$ & $98.10 \pm 0.57$ & $97.60 \pm 0.52$ & $97.60 \pm 0.52$ \\
& $\mathrm{RPE}(\mathrm{score})$ & $7.80 \pm 1.14$ & $8.80 \pm 1.32$ & $12.00 \pm 1.15$ & $13.9 \pm 1.97$ \\
& $\mathrm{METS}\left(\mathrm{w} / \mathrm{m}^{2}\right)$ & $1.27 \pm 0.51$ & $2.78 \pm 0.73$ & $4.34 \pm 1.06$ & $5.47 \pm 1.22$ \\
\hline
\end{tabular}

HR: heart rate, $\mathrm{SaO}_{2}$ : oxygen saturation, $\mathrm{RPE}$ : rating of perceived exertion, METs: metabolic equivalents. 
있는 시작 단계, 2 단계: 힘들지만 읽을 수 있는 단계, 3 단계: 힘들다 또는 운동자각도검사 점수 15 이상으로 나타나는 단계로 구성이 되고, 3 단 계가 되면 운동 검사가 종료 되었다. 산소포화도, 분당심박수, 대사당 량 등의 실제 측정값을 두 측정 방법 및 운동 단계에 따라 비교하였다.

\section{1) 트레드밀을 이용한 대화 검사}

트레드밀을 이용한 대화 검사는 수정된 Balke 프로토콜을 이용하였으며, ${ }^{14}$ 1 단계는 경사도 $0 \%$ 에서 각 대상자가 편안하게 걸을 수 있는 주관적 속도로 설정하여 4 분 동안 걷기를 수행하고, 그 후 매 2 분마다 경사도가 $2 \%$ 씩 증가 하여 걷기를 수행하였다. 운동 수행의 마지막에 대화 “국기에 대한 맹세” 낭송을 수행하고 검사자가 “편안하게 말할 수 있나요?”라는 질문에 응답 에 따라 운동의 강도를 증가시키게 된다. 매 2 분마다 수행이 끝나기 30 초 전에 시행하여 힘들지만 읽을 수 있는 단계가 되면 2단계로 설정을 하고, 힘들다 또는 운동자각도 검사 15 점 이상이 되면 3 단계로 설정하여 측정과 운동을 마무리하였다.

\section{2) 고정식 자전거를 이용한 대화 검사}

초기 고정식 자전거의 전력 출력은 $30 \mathrm{~W}$ 로 트레드밀과 동일하게 4 분 동안 편안한 속도로 운동을 수행하고, 그 후 매 2 분 간격으로 $30 \mathrm{~W}$ 씩 증가시켜 자전거 타기를 수행하였다. 그리고 운동 수행이 끝나기 30 초 전에 “국기에 대한 맹세” 낭송을 확인하여 1-3단계로 구분하여 측 정을 하였다.

\section{4. 자료 분석}

트레드밀과 고정식 자전거를 이용한 두 가지 형태의 유산소 운동을 적용하였을 때, 휴식 상태 및 대화 검사의 세 가지 단계에서 심박수, 산소포화도, 호흡에 대한 자각도, 대사당량의 차이를 비교 분석하기 위해 이요인 반복 측정 분산분석(two-way ANOVA with repeated measurement)을 사용하였다. 집단 간 요인(Between-group variance)은 유 산소 운동 형태로 집단 내 요인(within-group variance)은 대화 검사의 단계를 독립변수로 설정하였고, 정신 생리학적 반응 지표를 종속변 수로 설정하였다. 사후분석으로 각각의 대화 검사 단계에서 트레드 밀 집단과 자전거 집단 간의 종속변인의 차이 분석을 위해 독립 $\mathrm{t}$-검 정을 사용하였다. 피어슨 상관관계 분석을 활용하여 대화 검사의 단 계와 호흡에 대한 자각도의 상관관계를 분석하였다. 모든 통계 분석 은 윈도우용 IBM SPSS Statisics 22.0 을 사용하였고 통계적 유의 수준 은 $\alpha=0.05$ 로 설정하였다.

\section{결 과}

본 연구에 총 10 명의 대상자가 참여하였고, 남자 6 명, 여자 4 명으로 구
성되었다. 대상자의 일반적 특성으로 평균 나이는 $27.40 \pm 1.84$ 세였고, 평균 신장은 $167.80 \pm 8.23 \mathrm{~cm}$, 몸무게는 $69.10 \pm 15.95 \mathrm{~kg}$, 체질량지수는 $24.26 \pm 3.93$ 이었다.

대화 검사의 단계에 따라 트레드밀 집단과 자전거 집단에서 심박 수, 산소포화도, 호흡에 대한 자각도, 대사당량의 차이를 비교하기 위 한 이요인 반복측정분산분석 결과, 집단 간 주효과 검정 $(\mathrm{p}>0.05)$, 집 단 및 대화 검사 단계의 상호 작용 $(\mathrm{p}>0.05)$ 은 통계적으로 유의한 차 이를 보이지 않았다. 그러나 대화 검사 단계별 집단 내 주효과 검정 $(\mathrm{p}<0.05)$ 에서는 통계적으로 유의한 차이를 보였다.

휴식 상태 및 세 단계의 대화 검사에서 심박수, 산소포화도, 호흡 에 대한 자각도, 대사당량의 트레드밀 집단과 자전거 집단 간 차이 비 교에서 통게적으로 유의한 차이를 보이지 않았다( $\mathrm{p}>0.05)$. 유산소 운 동 단계와 호흡에 대한 자각도의 상관관계 분석에서 통계적으로 유 의한 높은 상관관계를 보였다 $(\mathrm{r}=0.870, \mathrm{p}<0.001)$.

\section{고 찰}

본 연구의 목적은 대화 검사가 유산소 운동 강도를 측정하는 것이 타 당한지를 알아보고, 실내 유산소 운동의 가장 대표적인 방법인 트레드 밀과 자전거를 이용한 운동 방법이 정신 생리학적 반응 지표에서 차이 가 나타나는지를 확인하는 것이다. 그 결과, 유산소 운동 강도에 따른 트레드밀 운동과 자전거 운동 간의 유의한 차이는 발견되지 않았고, 대화 검사의 각 단계별 차이는 통계적으로 유의한 차이를 보였다.

심박수의 측정에서, 트레드밀에서의 운동과 자전거에서의 운동이 휴식 상태와 대화 검사의 각 단계에서 통계적으로 유의한 차이를 보 이지 않았다. 그러나 트레드밀 운동이 자전거 운동에 비해 대화 검사 의 첫 번째 단계에서 5.50 , 두 번째 단계에서 6.17 , 세 번째 단계에서 10.33 만큼 더 높은 심박수가 일괄되게 나타났다. 산소포화도 및 호흡 에 대한 자각도의 측정에서, 트레드밀 집단과 자전거 집단에서 유산 소 운동 강도에 따른 통계적 유의성이 나타나지 않았다. 대사당량의 측정에서, 트레드밀을 이용한 유산소 운동과 자전거를 이용한 유산 소 운동이 운동 강도의 각 단계별로 통계적으로 유의한 차이를 보이 지 않았다. 그러나 트레드밀 운동이 자전거 운동에 비해 대화 검사의 두 번째 단계에서 0.42 , 세 번째 단계에서 0.94 만큼 더 높은 대사당량 을 일괄되게 보여 주었다.

운동 강도의 측정과 처방은 심장 및 호흡 재활의 평가와 치료를 위 한 기본적인 요소이며, 심호흡 기능을 유지하고 증진시키기 위한 접 근법의 근본이다. ${ }^{15}$ 운동 강도 측정을 위한 객관적인 방법으로 심박 수, 최대 산소 소비량(percentage of maximum oxygen consumption), 대 사당량, 여유 심박수(heart rate reserve) 등이 사용되고 있으며, 측정 방 법의 타당도와 신뢰도가 이미 확보되어 있다.1116-19 그러나 이러한 측 
정들은 측정 방법에 대한 숙련도, 측정 장비, 측정 시간 등에 대해 상 대적인 제한이 있다. 또한 운동자각도(rating of perceived exertion)는 낮은 단계의 심장 재활 프로그램 및 재가 훈련 프로그램에서 흔히 사 용되는 주관적인 운동 강도를 측정하는 방법이다. ${ }^{19}$ 그러나 피평가자 가 스스로 자각하는 운동 강도를 6 에서 20 까지 측정하는 방식으로, 교육 수준이 낮거나 인지 수준이 낮은 환자의 평가에서 사용하기 어 렵다. 반면 대화 검사는 특정한 장비를 사용하지 않고 간편하게 측정 할 수 있으며, 신경계 또는 심호흡 질환 등의 다양한 환자들에게 적용 할 수 있다. 본 연구 결과에서 대화 검사는 호흡에 대한 운동자각도 검사와 높은 상관관계를 보였으며, 이는 높은 신뢰도와 타당도를 입 증한 여러 선행 연구들과 일치하는 결과를 보였다.1118 Brawner 등 20 은 트랙 및 트레드밀 위에서 실시한 대화 검사에서 심박수와 높은 상관 관계가 나타났다고 보고하였고, Rodriguez Marroyo 등은 최대 산소 흡입량 $\left(\mathrm{VO}_{2}\right)$ 과 환기 역치(ventilatory threshold)에서 통계적으로 유의 한 높은 상관관계를 입증하였다.

트레드밀과 자전거를 이용한 유산소 운동의 비교에서 심박수, 산 소포화도, 호흡에 대한 운동자각도, 대사당량에서 모든 단계의 대화 검사에서 통계적으로 유의한 결과를 보이지 않았다. 통계적 유의성 이 나타나지 않은 것에 대한 이유로, 휴식 상태, 편안한 대화가 가능 한 상태, 대화가 다소 곤란한 상태, 대화가 전혀 힘든 상태에서 심박 수, 산소포화도, 운동자각도, 대사당량의 종속변수가 두 가지의 다른 유산소 운동의 차이를 변별하기에 측정 민감도(sensitivity)가 높지 않 았을 가능성이 있다. 또한 대상자의 표본 수가 작아서 통계적인 유의 성과 일반화를 도출하기 어려웠을 것이라 생각한다. 그러나 심박수 와 대사당량에서 운동 강도가 높은 단계로 갈수록 트레이드 밀에서 의 유산소 운동이 자전거에서의 보다 더 높은 생체 반응 지수를 보였 다. 많은 선행 연구들에 따르면, 트레이밀과 자전거를 이용한 유산소 운동 방법의 차이에 따라 혈압, 심박수, 최대 산소 흡입량, 젖산 축척 등의 여러 생체 반응 지표에서 운동 효과가 다르게 나타나며, 운동 방 법 그 차체의 장점이 있다고 보고 하였다.,21-27 Kisan 등 27 은 트레드밀 운동이 자전거 운동에 비해 더 높은 혈압과 심박수를 유발한다고 하 였고, Kravitz 등 ${ }^{26}$ 또한 트레드밀 운동이 상대적으로 더 높은 에너지 소비(energy expenditure)과 최대 산소 소비량을 보였다고 보고하였다. 이러한 선행 연구들이 결과를 종합해 보면, 트레드밀을 이용한 유산 소 운동이 자전거를 이용한 운동에 비해 운동 강도를 측정하기 위한 변별력이 더 높으며, 인체의 심혈관계 및 대사 반응에서 서로 다른 차 이를 보였다. 이러한 결과에 대한 설명력 있는 기전으로, 트레드밀에 서의 유산소 운동이 팔, 다리, 여러 몸통의 근육들을 활동 시켜 더 높 은 유산소 활동을 이끌어 내기 때문으로 생각된다.

최근 심장 및 호흡계 질환의 증가와 이에 따른 사회적 요구에 따라 여러 지역에서 전문치료센터가 설립되고 있으며, 심장 및 호흡 물리
치료 분야에 많은 관심과 필요성이 증가하고 있다. 운동의 강도에 따 른 환자의 정신 생리학적 반응 지표들을 측정하고 분석하는 것이 중 요하며, 다양한 객관적 또는 주관적인 측정 방법에 대한 지식과 기술 을 습득하는 것이 필요하다. 이미 전문가 집단에서 인정된 여러 운동 강도의 측정법이 있더라도, 대화 검사와 같이 임상에서 쉽고 간편하 고 빠르게 사용할 수 있는 측정법이 필요하다. 해외의 많은 연구들은 이미 대화 검사에 대한 타당도와 신뢰도를 입증하였고, 임상적 활용 과 다양한 분야의 연구에서 사용하고 있다. 하지만 국내에서는 대화 검사에 대한 연구는 전혀 알려져 있지 않았고, 임상에서도 많이 활용 되지 않고 있다. 본 연구에서 트레드밀과 자전거를 이용한 유산소 운 동에서의 정신생리학적 반응의 차이를 통계적인 차이를 발견하지 못 했지만, 대화 검사는 기존의 운동 강도를 측정하는 평가 방법과 높은 상관관계를 보였고 운동 강도에 따른 생체 반응이 일치하였음을 확 인하였다. 향후에는 많은 표본을 대상으로 심혈관 및 호흡에 관련된 객관적인 생체 반응 지표를 측정한다면 보다 유의미한 결과를 도출 하고 일반화된 결론을 도출할 수 있을 것으로 생각한다.

\section{ACKNOWLEDGEMENTS}

이 연구는 2019학년도 영남이공대학교 연구조성비 지원에 의한 것임.

\section{REFERENCES}

1. Sahron A. Plowman DLS. Exercise physiology for health, fitness, and performance. Lippincott Williams \& Wklkins. 2011.

2. Cooper KH. The benefits of exercise in promoting long and healthy lives - my observations. Methodist Debakey Cardiovasc J. 2010;6(4):10-2.

3. Thendral C. Metabolic and cadio respiratory responses between treadmill and erometer cycle. Dissertation of Master's Degree. 2016.

4. Ryu HY, Hong DS, Kim TH. The influence of maximal aerobic capacity on the two years cardiac related re-hospitalization in patients with heart failure with reduced ejection fraction in korean society. J Kor Phys Ther. 2019;31(5):322-7.

5. Park JH, Chung YJ. Comparison of aquatic treadmill and anti-gravity treadmill gait training to improve balance and gait abilities in stroke patients. J Kor Phys Ther. 2018;30(2):67-72.

6. Woltmann ML, Foster C, Porcari JP et al. Evidence that the talk test can be used to regulate exercise intensity. J Strength Cond Res. 2015;29(5): 1248-54.

7. Goode RC, Mertens R, Shaiman S et al. Voice, breathing, and the control of exercise intensity. Adv Exp Med Biol. 1998;450:223-9.

8. Rodriguez Marroyo JA, Villa JG, Garcia Lopez J et al. Relationship between the talk test and ventilatory thresholds in well-trained cyclists. J Strength Cond Res. 2013;27(7):1942-9.

9. Quinn TJ, Coons BA. The talk test and its relationship with the ventilatory and lactate thresholds. J Sports Sci. 2011;29(11):1175-82. 
10. Abiodun OO, Balogun MO, Akintomide AO et al. Comparison between treadmill and bicycle ergometer exercise tests in mild-to-moderate hypertensive nigerians. Integr Blood Press Control. 2015;851-5.

11. Zanettini R, Centeleghe P, Franzelli C et al. Validity of the talk test for exercise prescription after myocardial revascularization. Eur J Prev Cardiol. 2013;20(2):376-82.

12. Persinger R, Foster C, Gibson M et al. Consistency of the talk test for exercise prescription. Med Sci Sports Exerc. 2004;36(9):1632-6.

13. Nielsen SG, Vinther A. Graded cycling test combined with the talk test is responsive in cardiac rehabilitation. J Cardiopulm Rehabil Prev. 2016; 36(5):368-74.

14. Foster C, Porcari JP, Anderson J et al. The talk test as a marker of exercise training intensity. J Cardiopulm Rehabil Prev. 2008;28(1):24-30.

15. Reed JL, Pipe AL. The talk test: A useful tool for prescribing and monitoring exercise intensity. Curr Opin Cardiol. 2014;29(5):475-80.

16. Abell B, Glasziou P, Hoffmann T. The contribution of individual exercise training components to clinical outcomes in randomised controlled trials of cardiac rehabilitation: A systematic review and meta-regression. Sports Med Open. 2017;3(1):19.

17. Ballweg J, Foster C, Porcari J et al. Reliability of the talk test as a surrogate of ventilatory and respiratory compensation thresholds. J Sports Sci Med. 2013;12(3):610-1.

18. Petersen AK, Maribo T, Hjortdal VE et al. Intertester reliability of the talk test in a cardiac rehabilitation population. J Cardiopulm Rehabil Prev. 2014;34(1):49-53.

19. Hansen D, Stevens A, Eijnde BO et al. Endurance exercise intensity de- termination in the rehabilitation of coronary artery disease patients: A critical re-appraisal of current evidence. Sports Med. 2012;42(1):11-30.

20. Brawner CA, Vanzant MA, Ehrman JK et al. Guiding exercise using the talk test among patients with coronary artery disease. J Cardiopulm Rehabil. 2006;26(2):72-5; quiz 6-7.

21. Bouckaert J, Vrijens J, Pannier JL. Effect of specific test procedures on plasma lactate concentration and peak oxygen uptake in endurance athletes. J Sports Med Phys Fitness. 1990;30(1):13-8.

22. Coyle EF, Feltner ME, Kautz SA et al. Physiological and biomechanical factors associated with elite endurance cycling performance. Med Sci Sports Exerc. 1991;23(1):93-107.

23. Jacobs I, Sjodin B. Relationship of ergometer-specific vo2 max and muscle enzymes to blood lactate during submaximal exercise. Br J Sports Med. 1985;19(2):77-80.

24. Scott CB, Littlefield ND, Chason JD et al. Differences in oxygen uptake but equivalent energy expenditure between a brief bout of cycling and running. Nutr Metab (Lond). 2006;31.

25. Hsia D, Casaburi R, Pradhan A et al. Physiological responses to linear treadmill and cycle ergometer exercise in copd. Eur Respir J. 2009;34(3): 605-15.

26. Kravitz L, Robergs RA, Heyward VH et al. Exercise mode and gender comparisons of energy expenditure at self-selected intensities. Med Sci Sports Exerc. 1997;29(8):1028-35.

27. Ravikiran Kisan SRK, Anitha OR, Chandrakala SP Treadmill and bicyle ergometer exercise: Cardiovascular response comparison. Glob J Med Res. 2016;12(5):1-5. 